\title{
Correction to: Fiber Optic Communications
}

\section{Correction to: \\ G. Keiser, Fiber Optic Communications, https://doi.org/10.1007/978-981-33-4665-9}

The original version of the book was inadvertently published with incorrect sentences in Chapters 1, 3, 5, 8, 10 and 13. The sentences have now been corrected. The book has also been updated with these changes.

The updated versions of these chapters can be found at https://doi.org/10.1007/978-981-33-4665-9_1 https://doi.org/10.1007/978-981-33-4665-9_3 https://doi.org/10.1007/978-981-33-4665-9_5 https://doi.org/10.1007/978-981-33-4665-9_8 https://doi.org/10.1007/978-981-33-4665-9_10 https://doi.org/10.1007/978-981-33-4665-9_13 